\title{
Monosodium Glutamate in the Diet Does Not Raise Brain Glutamate Concentrations or Disrupt Brain Functions
}

\author{
John D. Fernstrom \\ Department of Psychiatry, Department of Pharmacology and Chemical Biology, University of Pittsburgh School of \\ Medicine, Pittsburgh, PA, USA
}

\section{Keywords \\ Blood-brain barrier - Circumventricular organ - Extracellular fluid - Follicle-stimulating hormone - Growth hormone . Glutamic acid · Luteinizing hormone - Monosodium glutamate - N-methyl-d-aspartate - Prolactin - Thyrotropin releasing hormone . Thyroid stimulating hormone}

\begin{abstract}
The non-essential amino acid glutamate participates in numerous metabolic pathways in the body. It also performs important physiologic functions, which include a sensory role as one of the basic tastes (as monosodium glutamate [MSG]), and a role in neuronal function as the dominant excitatory neurotransmitter in the central nervous system. Its pleasant taste (as MSG) has led to its inclusion as a flavoring agent in foods for centuries. Glutamate's neurotransmitter role was discovered only in the last 60 years. Its inclusion in foods has necessitated its safety evaluation, which has raised concerns about its transfer into the blood ultimately increasing brain glutamate levels, thereby causing functional disruptions because it is a neurotransmitter. This concern, originally raised almost 50 years ago, has led to an extensive series of scientific studies to examine this issue, conducted primarily in ro-
\end{abstract}

dents, non-human primates, and humans. The key findings have been that (a) the ingestion of MSG in the diet does not produce appreciable increases in glutamate concentrations in blood, except when given experimentally in amounts vastly in excess of normal intake levels; and (b) the blood-brain barrier effectively restricts the passage of glutamate from the blood into the brain, such that brain glutamate levels only rise when blood glutamate concentrations are raised experimentally via non-physiologic means. These and related discoveries explain why the ingestion of MSG in the diet does not lead to an increase in brain glutamate concentrations, and thus does not produce functional disruptions in brain. This article briefly summarizes key experimental findings that evaluate whether MSG in the diet poses a threat to brain function.

(c) 2018 The Author(s)
Published by S. Karger AG, Basel

\section{Introduction}

In the 1970s, food additives in the United States were reviewed for safety by the Food and Drug Administration. One of them, monosodium glutamate (MSG, the sodium salt of glutamic acid [GLU]), came under in-

\begin{tabular}{|c|c|c|}
\hline KARGER & $\begin{array}{l}\text { (c) } 2018 \text { The Author(s) } \\
\text { Published by S. Karger AG, Basel }\end{array}$ & $\begin{array}{l}\text { Karger } \\
\text { Open access }\end{array}$ \\
\hline $\begin{array}{l}\text { E-Mail karger@karger.com } \\
\text { www.karger.com/anm }\end{array}$ & $\begin{array}{l}\text { This article is licensed under the Cre } \\
\text { NonCommercial-NoDerivatives } 4.0 \\
\text { BY-NC-ND) (http:///www.karger.com } \\
\text { se). Usage and distribution for comm } \\
\text { distribution of modified material requ }\end{array}$ & $\begin{array}{l}\text { mmons Attribution- } \\
\text { ational License (CC } \\
\text { es/OpenAccessLicen- } \\
\text { urposes as well as any } \\
\text { itten permission. }\end{array}$ \\
\hline
\end{tabular}

John D. Fernstrom, PhD

Western Psychiatric Institute and Clinic

3811 O'Hara Street

Pittsburgh, PA 15238 (USA)

E-Mail fernstromjd@upmc.edu 
tense scrutiny following the publication of a report that the subcutaneous injection of large doses of MSG into newborn mice caused rapid degenerative changes in brain. The most notable effects occurred in a specific region of the brain (the median eminence and the arcuate nucleus portions of the hypothalamus) that controls the secretion of several pituitary hormones. When these animals grew to adulthood, they were found to be of below normal body length ("stature") and obese, and have difficulty reproducing [1]. These effects were all consistent with disturbed hypothalamic and pituitary functions. A notable feature of this model was that clear anatomic evidence of neuronal destruction in the hypothalamus was observable only for the first $12-24 \mathrm{~h}$ after MSG administration. Thereafter, hypothalamic damage was no longer evident. But functional consequences became clear when animals grew to adulthood. At the time, the author speculated that MSG ingestion by pregnant women might imperil the normal development of the fetal nervous system [1]. In subsequent studies, the author suggested that weaning infants onto normal food containing MSG might also lead to hypothalamic lesions [2].

Over time, a complete hypothesis regarding foodrelated neurotoxicity, with MSG as a dominant perpetrator, took shape. It posited that the ingestion of MSG in food would cause GLU to be absorbed by the intestines and enter blood, raising plasma GLU concentrations. If enough MSG was ingested, plasma GLU levels would rise high enough to elevate GLU levels in a small number of brain regions called the circumventricular organs (CVOs), most notably the median eminence that lies at the base of the brain, just above the pituitary gland. These areas lack a "blood-brain barrier" (BBB), so that small and large molecules in blood freely penetrate into them [3]. The endothelial cells that make up the capillaries in the brain are, for the most part, joined by tight junctions. These cells are thus the physical representation of the BBB, as all molecules entering or exiting brain must pass directly through them. The endothelial cells, using a variety of mechanisms, allow some molecules to pass into and out of the brain, both actively and passively, and prevent the inward movement of still others [3]. For GLU, the BBB on balance prevents the movement of GLU from the blood into the brain. But such is not the case for the CVOs, where the endothelial cells are not tightly joined together, and molecules like GLU easily pass around them into and out of the extracellular fluid (ECF) [3]. Hence, when plasma GLU rises, ECF GLU levels in the CVOs rise as well, notably in the median eminence [4]. Adjacent to the me- dian eminence is the arcuate nucleus of the hypothalamus, which contains neurons that send their axons into the median eminence, where they terminate on and release signaling molecules into the capillaries. These molecules (pituitary releasing factors) travel a short distance via the local blood supply to the pituitary, where they direct the release of one or more hormones. Arcuate nucleus neurons are normally protected from median eminence ECF by a "substitute" BBB, physically represented by glial cells (tanycytes) that block the free movement of molecules in median eminence ECF into that of the arcuate nucleus. But, when ECF GLU becomes very high, GLU can penetrate into the arcuate nucleus ECF [5]. GLU is an excitatory neurotransmitter, causing neurons to depolarize [6]. When neurons are exposed to too much GLU, they become overstimulated and die [7]. So, according to the GLU neurotoxicity hypothesis [8], when median eminence ECF GLU levels rise to very high levels, GLU penetrates into the arcuate nucleus, raises arcuate ECF GLU levels [4], overstimulates many arcuate neurons, causing their death and ending their ability to direct the function of the pituitary gland. A later addendum to this hypothesis posited that doses of MSG that did not raise median eminence and arcuate ECF GLU concentrations high enough to kill arcuate neurons, if sufficiently high, could nonetheless stimulate arcuate neurons, causing them to fire at abnormally high rates, and transiently disrupt their functions. Such intermittent disruptions throughout post-natal development and maturation were then conjectured to lead to permanent abnormalities in adult brain function without causing MSG-induced neuronal death [8].

This hypothesis was examined experimentally beginning in the 1970s, with studies divided roughly into 3 categories. The first identified the peak plasma GLU concentrations and the occurrence of hypothalamic lesions as a function of MSG dose and route of administration. The second examined the effects of feeding animals MSG (added to their food or water) chronically, looking for the occurrence of pathophysiologic effects in adults like those produced by injections of MSG. And the third studied non-human primates and humans, looking at the plasma GLU changes that accompanied MSG ingestion, alone and in foods and beverages, and then exploring for brain effects. These studies are reviewed below. Taken together, the findings strongly support the conclusion that the ingestion of MSG by humans does not push GLU into the brain, as most clearly evidenced by the absence of alterations in the secretion of pituitary hormones.
Fernstrom 


\section{Plasma GLU Concentrations and the Occurrence of Hypothalamic Lesions}

A single subcutaneous injection of MSG into newborn mice causes rapid damage to neurons in the arcuate nucleus of the hypothalamus [1]. Administered repeatedly over several days, MSG also causes long-lasting consequences to body functions $[1,9]$. Numerous studies followed the initial report of these effects, examining the hypothalamic neurotoxic effects of MSG injection in mice and other animals [10], and assessing whether oral administration of MSG would elicit the same effects. A few attempted to identify dose-response relationships. Since the hypothesis required increases in plasma GLU and subsequently arcuate GLU concentrations to cause arcuate neurotoxicity, some studies examined the magnitude of increase required in plasma GLU concentration needed to produce arcuate lesions. These studies compared the increases in plasma GLU following MSG injection, oral intubation, and ingestion in food. They examined arcuate neuronal death microscopically as their endpoint, which occurred within the first 12-24 h after treatment, and thereafter was barely visible $[11,12]$.

The rise in plasma GLU following MSG injection (subcutaneous or intraperitoneal) is immediate, substantial, and of short duration. For example, following an injected dose of $1,000 \mathrm{mg} / \mathrm{kg}$ bw in adult mice, plasma GLU rises to a peak within 15 min that is about 50 -fold above baseline values. If MSG is given in water via stomach tube to fasting animals, the increase is still substantial, though somewhat less (about 35-fold over baseline). Similar effects were observed when the same treatments were given to infants and weanling mice [13]. If the same dose of MSG was given in food, however, the rise in plasma GLU was substantially attenuated in all age groups [13].

In weanling mice, the threshold MSG dose for neuronal damage in the arcuate nucleus was examined following subcutaneous injection. A dose of $700 \mathrm{mg} / \mathrm{kg}$ bw was the lowest subcutaneous dose at which observable arcuate lesions were evident, and caused a 38 -fold rise in plasma GLU concentrations [14]. To examine the effect of food on this neurotoxic effect, infant mice were weaned onto a normal mouse diet containing 5,10 , or $15 \%$ added MSG [15]. Groups were killed each day for the first 4 post-weaning days, $3 \mathrm{~h}$ after the onset of the daily dark period, a time when they would have consumed a substantial amount of MSG in their food (rodents normally begin eating their first large meal of the day around dark onset [16]). Their hypothalami were examined for evidence of neurotoxicity. None was found. Their food in-

Dietary MSG and Brain Function take was monitored daily and their daily MSG doses calculated. The animals consumed 10,000-30,000 mg/kg bw/day MSG, depending on the MSG content of the diet. Animals consuming $15 \%$ the MSG diet would ingest $3,000-4,000 \mathrm{mg} / \mathrm{kg}$ bw MSG during just the 3-hr period after dark onset (see [17]). In a 24-h study of weanling animals ingesting $10 \%$ or $15 \%$ MSG in their diets, plasma GLU concentrations during this 3-h window ranged between 200 and $1,500 \mathrm{nmol} / \mathrm{mL}$, well below the threshold concentration $(3,850 \mathrm{nmol} / \mathrm{mL})$ associated with the emergence of arcuate neurotoxicity [17]. As a positive control in this study, a group of weanling animals received a subcutaneous injection of MSG $(4,000 \mathrm{mg} / \mathrm{kg}$ bw) and were killed $8 \mathrm{~h}$ later. This latter group showed marked neuronal death in the arcuate nucleus [15]. The logic of this study is useful to ponder. Olney administered MSG to infant mice by injection at doses of 500 $4,000 \mathrm{mg} / \mathrm{kg}$ and looked for hypothalamic damage several hours later [1]. The above dietary study did essentially the same thing, except that the animals self-administered the highest dose of MSG by eating it with food. They were examined in the same time window after administration that one would expect to see lesions, if they occurred. The study looked at animals after 1 day of self-administration, and then (in other groups) after 2, 3 , or 4 days of self-administration, in all cases looking at the arcuate nucleus around $3 \mathrm{~h}$ into the main meal period of the day. No lesions resulted.

These data thus indicate in rodents that while injection or rapid intubation of enormous doses of MSG can rapidly elevate plasma GLU concentrations to a high enough level to induce arcuate neurotoxic lesions (possibly by elevating arcuate GLU concentrations $[4,18]$ ), when such extreme doses are ingested with food, plasma GLU levels do not rise sufficiently to cause arcuate lesions.

The newborn/infant mouse has generally been viewed as the most susceptible to arcuate lesions induced by MSG. Weanling and adult animals were found to require much higher doses of MSG to produce arcuate lesions (e.g., see reference [12]). This aging effect in rodents may be related to the fact that the bulk of brain development in rodents, unlike humans, occurs post-natally (see reference [19]), and is attributable to the post-natal development and maturation of tanycytes (a type of glial cell) in the median eminence. Tanycytes appear in the median eminence only after birth in rodents, with a full complement present around post-natal day 30 [5]. Arcuate neurotoxicity to MSG was found to diminish as the newborn mouse aged in parallel with tanycycte emergence in the median eminence. The development of tanycytes was 
shown to supply a "BBB" analog to capillary endothelial cells, providing this barrier to GLU penetration from the median eminence into the arcuate nucleus [5].

\section{Does Feeding MSG Chronically Elicit Pathophysiologic Effects Like Those Induced by Injecting Infant Animals with MSG?}

Another approach to assessing the impact of MSG ingestion on hypothalamic function is to feed animals MSG chronically and examine their developmental outcomes. The measured endpoints would be those aberrations that appear in adulthood when high-dose MSG is administered by injection early in post-natal life. These signs would include shortness of stature, obesity, and infertility $[1,9]$. A great number of such studies have been conducted over the years, with no adverse effects found (e.g., see reference [10]). The most extensive experiment was a 3 -generation study, in which male and female mice were fed a standard lab diet, or a diet to which 1 or $4 \%$ MSG (by weight) had been added [20]. Within each diet group (basal, 1\% MSG or 4\% MSG diet), animals ingested their respective food source throughout life, which included their reproductive periods. The first generation $\left(\mathrm{F}_{1}\right)$ was derived from animals that had been fed one of the 3 diets from weaning through their reproductive cycle. They continued on the same diet throughout their lives, with their offspring constituting the second generation $\left(\mathrm{F}_{2}\right)$. The life cycle was repeated again to create a third generation $\left(\mathrm{F}_{3}\right)$. Hence, all animals $\left(\mathrm{F}_{1}, \mathrm{~F}_{2}, \mathrm{~F}_{3}\right)$ were exposed to dietary MSG during conception, in utero development, birth, infancy, and adulthood. Their food intake, MSG intake, and body weights were measured daily, their reproductive performance assessed, and ultimately their hypothalami examined histologically for abnormalities. The intake of MSG reached as high as 7,000 mg/kg bw/ day in females (4\% MSG diet), and in lactating females as high as $25,000 \mathrm{mg} / \mathrm{kg} /$ day (4\% MSG diet). The animals in all groups showed normal growth rates, body weights (no obesity), and measures of reproductive function. No alteration in arcuate nucleus neuronal density was observed in animals consuming MSG, compared to those ingesting the basal diet. (Olney had reported that the death of arcuate neurons following MSG injection early in life leaves a tell-tale sign in the mature arcuate nucleus of being populated by a low total number of neurons [11]. This was not the case in this multi-generation dietary study.) Hence, the expected physiologic and neuroanatomic signs of neuronal death in the arcuate nucleus resulting from MSG injection are not present in animals consuming enormous amounts of MSG through several life cycles.

\section{Non-Human Primate and Human Studies}

The most important evaluation of MSG safety is in humans. Is it safe to administer high doses of MSG to humans? Can useful and convincing studies be conducted in humans? What measurements have been made, and why?

MSG is safe to study in humans at very high doses. It has been administered in experiments for over 60 years, in most cases to adults as a single, oral dose up to $150 \mathrm{mg} / \mathrm{kg} \mathrm{bw}$ (e.g., references [21-23]), but also chronically, for up to 6 weeks at daily doses up to $150,000 \mathrm{mg} /$ day (about 2,000 mg/kg bw/ day for a $70 \mathrm{~kg}$ person) [24] and for 12 weeks at daily doses up to $45,000 \mathrm{mg} /$ day (about $600 \mathrm{mg} / \mathrm{kg} \mathrm{bw} /$ day, in three divided doses of $5 \mathrm{~g}$ [i.e., about $200 \mathrm{mg} / \mathrm{kg}$ at each dosing]) [25]. Only minor side effects, typically nausea, have occasionally been reported at such high doses [25].

High doses of MSG have also been administered to nonhuman primates (monkeys), permitting a direct assessment of whether hypothalamic lesioning occurs. Several studies have been conducted in infant primates, and the broad conclusion is that MSG does not induce neuronal degeneration in the arcuate nucleus of the hypothalamus (see [26]). In such studies, MSG has been most typically administered by subcutaneous injection or oral intubation [27-31], to mimic the design of rodent studies. Doses have ranged from 1,000 to $4,000 \mathrm{mg} / \mathrm{kg}$ bw. Animals have been sacrificed 3-6 h after administration, because of the transient nature of MSG-induced arcuate lesions seen in rodents. In newborn monkeys, fasting plasma GLU concentrations are around $10 \mathrm{nmol} / \mathrm{mL}$, and rise to peak values some 17 -fold (1,000 mg/kg bw dose) to 33 -fold (4,000 mg/ $\mathrm{kg}$ bw dose) above baseline values within $1 \mathrm{~h}$ of oral administration [32]. Such enormous increases in plasma GLU concentrations are in the range of those observed in rodents (see above). It is also noteworthy in this regard (discussed further below) that in monkey studies of pituitary function (the release of pituitary hormones into blood), no adverse effects on pituitary function have resulted from multiple, sequential injections of very high doses of MSG or GLU receptor agonists (kainic acid, N-methyl-d-aspartate [NMDA]) [33, 34]. These latter findings indicate that functionally, arcuate neurons and endocrine cells of the pituitary are not damaged by such treatments.

Since MSG can be administered safely to humans in high doses, can this species be examined to determine if
Fernstrom 
the ingestion of MSG causes GLU levels to rise sufficiently in blood to penetrate into brain? We cannot at present look directly into the human brain, and determine if specific neurons are firing at abnormally high rates in the hypothalamus. But we can obtain a reliable, indirect measure of arcuate neuronal function through the measure of pituitary hormone secretion. Quite apart from the subject of this review, neuroendocrinologists have long studied the control of pituitary hormone secretion by hypothalamic neurons (including those in the arcuate nucleus). The approach most relevant to the present discussion involves identifying neurochemically specific neurons that control the secretion of individual pituitary hormones. Evidence can be obtained in animals by measuring the secretory response (blood hormone changes) to the administration of known agonists and antagonists of receptors for particular transmitters. Such drugs have been injected in minute amounts directly into the brain areas of interest, or by peripheral injection, and the hormonal responses measured in blood. Precursors of a particular transmitter can be administered to stimulate the production and release of that transmitter. Drugs that prevent inactivation of a transmitter, once released into the synapse, can also be examined. Typically, one expects to find that direct-acting agonists, precursors that stimulate the synthesis and release of a particular transmitter, and drugs that prevent the inactivation of a transmitter, once released into the synapse, should affect the secretion of the pituitary hormone of interest in the same way (consistently increase or decrease it). Drugs that block the receptors for a particular transmitter should be able to block the effects of an agonist, precursor or inactivator. A good example of the application of this paradigm is the study of the role of serotonin neurons in controlling the secretion of pituitary hormones. These neurons project their axons from brainstem areas into regions of the hypothalamus that control pituitary hormone secretion, including the arcuate nucleus. And, their impact on the secretion of these pituitary hormones has been examined using all of the pharmacologic approaches noted immediately above [35]. The consistency of the relationship of the effect of different serotonin drugs on prolactin secretion, for example, has led to its successful application to the indirect assessment of serotonin synaptic function in the brains of humans (e.g., depressed patients) [36]. The subject is administered a particular serotonin drug (such as a precursor or an agonist), and multiple blood samples are drawn at frequent intervals over several hours, and the pituitary hormone of interest measured. This approach has led to the conclusion that serotonin neurotransmission is below

Dietary MSG and Brain Function normal in depressed patients (which helps to explain why drugs that improve serotonin release by neurons improve mood in depressed patients) [36].

This same paradigm has been applied to examine the effect of MSG on pituitary hormone secretion in humans [22]. As noted above for serotonin neurons, there is good reason to think that GLU neurons projecting into the hypothalamus (and the arcuate nucleus) are involved in the regulation of pituitary hormone secretion. Essentially all neurons in the arcuate nucleus, for example, receive excitatory synaptic inputs from GLU nerve terminals [37]. Neurons in the arcuate nucleus (and other hypothalamic nuclei) that control pituitary function express the main GLU receptor subtypes (e.g., kainic acid, NMDA). Moreover, the injection of agonists selective for each receptor subtype stimulates the secretion of gonadotropin releasing hormone, growth hormone (GH), and prolactin [38]. Hence, given that the administration of high doses of MSG to humans has repeatedly been shown to be safe, one can safely examine in humans whether the ingestion of a high oral dose of MSG, that causes a marked elevation in plasma GLU concentrations, causes the release of pituitary hormones. If so, the result would suggest that the plasma GLU level has reached a level sufficient to penetrate into the arcuate nucleus and stimulate arcuate neurons that control pituitary hormone secretion.

Our group conducted such an experiment [22]. Based on a prior study, we knew that a single, oral dose of $150 \mathrm{mg} /$ kg MSG by overnight-fasted subjects would cause an enormous rise in plasma GLU concentrations [21]. We, therefore, designed a study to compare the effect of this dose of MSG and a placebo (in the same subjects on separate days) on the secretion of several pituitary hormones over $4 \mathrm{~h}$ following ingestion. The pituitary hormone of greatest interest was prolactin, since a previous study of several amino acids had reported a small effect of GLU (not MSG) ingestion $(10 \mathrm{~g})$ on this hormone [39], and MSG injection had been reported in rats to rapidly elevate plasma prolactin levels [40]. We also included two "positive controls," one pharmacologic (a thyrotropin releasing hormone [TRH] challenge test, which markedly stimulates prolactin secretion [41]) and the other physiologic (the ingestion of a high-protein meal, which causes a small but statistically significant rise in prolactin secretion $[42,43])$. The inclusion of such positive controls would validate our experimental design, if they reproduced 2 previously reported effects, and also provide physiologic and pharmacologic comparators with any effects seen with MSG.

The subjects were healthy males (age $\sim 25$ years, $\sim 80 \mathrm{~kg}$, $n=8$ ), who received each of four treatments on separate

Ann Nutr Metab 2018;73(suppl 5):43-52 DOI: $10.1159 / 000494782$ 
Fig. 1. Plasma glutamate concentrations in subjects ingesting MSG, placebo, a protein meal, or receiving intravenous TRH. Each subject received each treatment, on different days, at $0830 \mathrm{~h}(0 \mathrm{~min})$ after an overnight fast. Blood samples were collected every $20 \mathrm{~min}$ for $4 \mathrm{~h}$. a White dots, MSG (12.7 g) solution; black dots, placebo solution. $\mathbf{b}$ White triangles, TRH (100 $\mu$ g i.v.) infusion; black triangles, protein meal. Data are mean $\pm \mathrm{SD}(n=8)$. Analysis of variance revealed significant effects of treatment $(\mathrm{F}=$ 95.6; $p<0.001)$ and time $(\mathrm{F}=8.1 ; p<0.01)$, and a significant time $\mathrm{X}$ treatment interaction $(\mathrm{F}=7.6 ; p<0.01)$. A comparison of MSG with placebo was statistically significant, whereas that of the protein meal with placebo was not (post-hoc testing). From reference [22], with permission. MSG, monosodium glutamate; $\mathrm{TRH}$, thyrotropin releasing hormone.

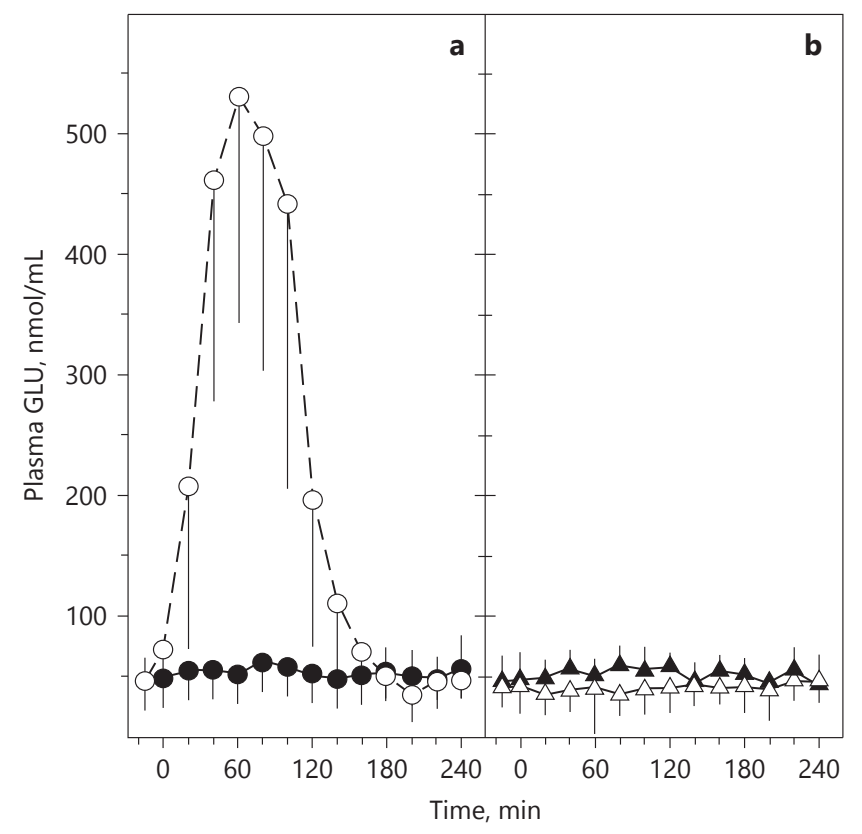

The finding that plasma prolactin levels (and the levels of other pituitary hormones) did not rise in the face of a marked, 11-fold rise in plasma GLU concentrations indicates that GLU has not penetrated into the arcuate nucleus. Would a higher increase in plasma GLU elicit a response? Higher doses have not been attempted in humans (there is no reason to do so: see discussion below), but intravenous doses of GLU have been given to monkeys that produce even greater increases in plasma GLU than those seen in humans. In these studies, an intravenous dose of $150 \mathrm{mg} / \mathrm{kg}$ MSG rapidly raised plasma GLU concentrations about 50 -fold, and did produce a significant increase in plasma LH levels $[33,44]$. Such results suggest that there is a threshold in plasma GLU levels above which GLU can reach the arcuate nucleus from the circulation (which is greater than an 11-fold rise, but less than a 50 -fold rise). However, such a conclusion must be tempered by the fact that GLU receptors are also found on the hormone-secreting cells of the pituitary gland themselves (see reference [6]). And, the pituitary endocrine cells release $\mathrm{GH}, \mathrm{LH}$, and prolactin in response to elevated GLU concentrations (see reference [6]). These cells have no BBB to protect them, and thus are exposed to the concentrations of GLU found in the circulation. Hence, the increase in $\mathrm{LH}$ secretion seen after a 50-fold rise in plasma GLU may have been in response to direct stimulation of pituitary LH-secreting cells, rather than an indirect effect mediated by arcuate neurons control-
Fernstrom 


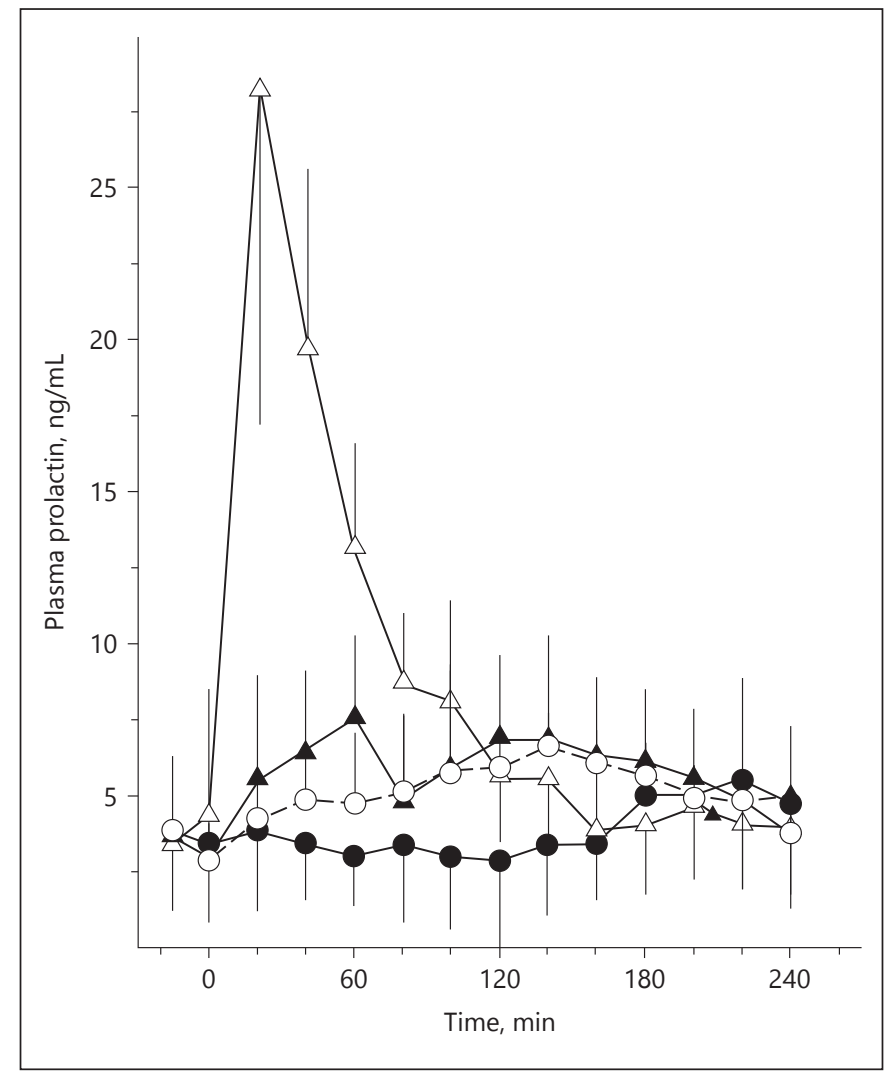

Fig. 2. Plasma prolactin levels in subjects ingesting MSG, placebo, a protein meal, or receiving an i.v. infusion of TRH. Data are mean $\pm \mathrm{SD}(n=8)$. Group symbols are the same as those described in Figure 1. Analysis of variance showed significant effects of time $(\mathrm{F}=14.29 ; p<0.01)$ and treatment $(\mathrm{F}=12.86 ; p<0.01)$, and a significant time $\mathrm{X}$ treatment interaction $(\mathrm{F}=23.78$; $p<0.01)$. Posthoc testing revealed significant group effects for TRH and the protein meal, but not MSG, compared to the placebo treatment. From reference [22], with permission. MSG, monosodium glutamate; $\mathrm{TRH}$, thyrotropin releasing hormone.

ling LH secretion. In this context, it is also worth noting that the absence of increases in the plasma levels of any of the pituitary hormones measured in our human study indicates that pituitary cells bearing GLU receptors are apparently unresponsive to the 11 -fold increases in the GLU concentrations to which they were exposed.

\section{How High Do Plasma GLU Concentrations Increase When Humans Consume MSG in the Diet?}

The above discussion has focused on the magnitude of increase in plasma GLU concentrations following MSG administration. In rodents, the increase needed to produce arcuate lesions is typically in the $30-50$-fold range $[14,45]$. In monkeys, large doses of MSG produce increases of 17 -fold $(1,000 \mathrm{mg} / \mathrm{kg}$ bw, by stomach tube) and 33 -fold $(4,000 \mathrm{mg} / \mathrm{kg}$ bw, by stomach tube), but are associated with no arcuate lesions [26, 32]. Additionally, a dose of MSG that stimulated LH secretion in monkeys $(150 \mathrm{mg} / \mathrm{kg}$, given intravenously) produced a 50 -fold rise in plasma GLU concentrations [44]. In humans, the increase in plasma GLU produced by MSG $(150 \mathrm{mg} / \mathrm{kg}$, given orally) is around 11-fold [22], and is associated with no pituitary hormone changes in plasma, indicating MSG has not penetrated into the arcuate nucleus (or stimulated hormone secretion directly in the anterior pituitary [6]).

How much does plasma GLU normally rise in plasma with the ingestion of food and MSG in humans? In the human study discussed above, subjects ingested $90 \mathrm{~g}$ of protein in a single test meal and showed no significant rise in plasma GLU concentrations (Fig. 1). The protein would have contained about $9 \mathrm{~g}$ of GLU (about $130 \mathrm{mg} /$ $\mathrm{kg}$ bw GLU for a $70 \mathrm{~kg}$ individual), but no net GLU passed from the intestines into the systemic circulation. By way of reference, the average daily intake of protein in the American diet is almost the same, about $100 \mathrm{~g}$ [46]. This lack of increase in plasma GLU concentration most likely is a reflection of the extraordinary ability of intestinal cells to metabolize GLU [47]. In another, single meal study, supplying $70 \mathrm{~g}$ protein in familiar food items (hamburger/bun/milk shake), a rise in plasma GLU was reported, and was about 2.3-fold (over baseline values) within a few hours $[48,49]$. When MSG was added to this meal, the total rise in plasma GLU was about 2.8 -fold (over baseline values) at $34 \mathrm{mg} / \mathrm{kg}$ and about 4.1 -fold (over baseline) at $150 \mathrm{mg} / \mathrm{kg}[48,49]$. If instead, the meal was a bowl of simple broth (consommé), the rise in plasma GLU from the broth alone was 1.5-fold in adults and 1.1-fold in 1-year old infants, and with the addition of $50 \mathrm{mg} / \mathrm{kg}$ MSG, was 4.5 -fold in adults and 1.8-fold in infants $[50,51]$. Additionally, the impact on plasma GLU concentrations has been examined in a diurnal study in humans ingesting a normal diet [52]. The subjects ingested a standardized diet on one test day, and the same diet containing MSG (100 mg/ $\mathrm{kg}$ bw/day: $15 \mathrm{mg} / \mathrm{kg}$ bw at breakfast, $40 \mathrm{mg} / \mathrm{kg}$ bw at lunch, and $45 \mathrm{mg} / \mathrm{kg}$ bw at dinner) on a second test day. Blood was sampled throughout the 24 -h period. As indicated in Figure 3, small variations occurred in plasma GLU concentrations over the 24 -h period on both test days, and small (about 2 -fold) increases in plasma GLU were noted soon after lunch and dinner on both test days. 
Fig. 3. Twenty-four hour variations in plasma glutamate concentrations in 10 adult men ingesting a standard diet without (black circles) or with (white circles) added monosodium glutamate (MSG; 100 mg/kg/ day). Data are expressed in $\mathrm{nmol} / \mathrm{mL}$; vertical bars represent SD. The study was conducted in an in-patient nutrition unit. Arrows indicate the time of ingesting meals (B, breakfast; L, lunch; D, dinner) and snacks (s). The $100 \mathrm{mg} / \mathrm{kg} /$ day dose was divided and given as $15 \mathrm{mg} / \mathrm{kg}$ at breakfast, $40 \mathrm{mg} / \mathrm{kg}$ at lunch, and $45 \mathrm{mg} / \mathrm{kg}$ at dinner. Values at different time points with the same letters (for black circles) or numbers (for white circles) are significantly different ( $p<0.05$; repeated-measures analysis of variance, Bonferroni $t$ test). Adapted from reference [52], with permission. MSG, monosodium glutamate.

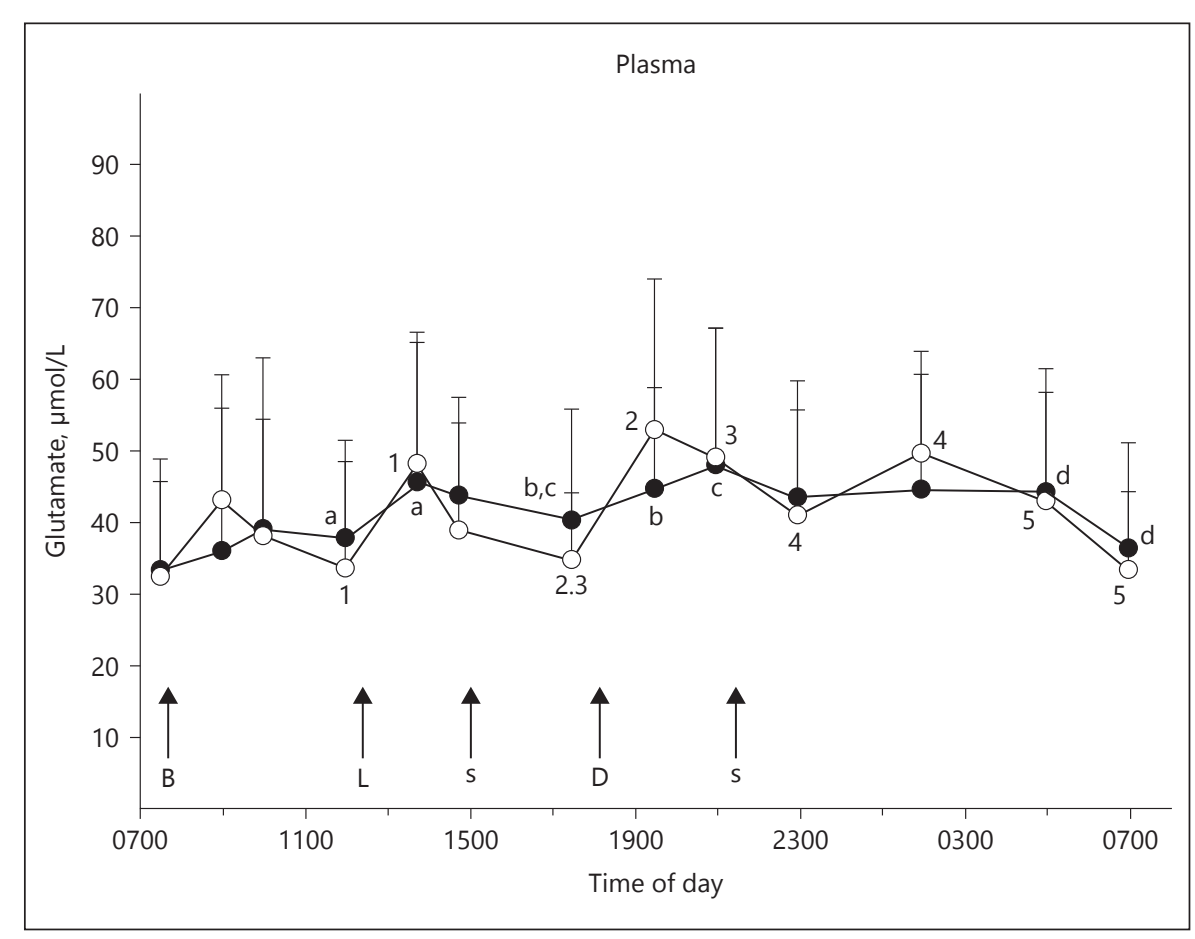

Since an 11-fold rise in plasma GLU concentrations following ingestion of $150 \mathrm{mg} / \mathrm{kg}$ MSG in a non-caloric liquid produces no change in pituitary hormone secretion in adult humans, indicating no penetration of GLU into the arcuate nucleus, the much smaller increases in plasma GLU concentrations that accompany the ingestion of foods with or without added MSG indicate that no arcuate penetration occurs in these dietary scenarios as well (in infants or adults). The findings, therefore, suggest that if there is a single-dose amount of MSG that will stimulate pituitary hormone secretion, it is above the 150 $\mathrm{mg} / \mathrm{kg}$ bw dose associated with a no effect response. Since humans find foods containing MSG at high concentrations to be unpalatable [53], they are unlikely ever to ingest MSG at a dose of $150 \mathrm{mg} / \mathrm{kg}$ bw in a food source.

\section{Conclusions}

This review has attempted to explain why studies in rodents injected with massive doses of MSG are not particularly useful in evaluating the safety of MSG in the human food supply with regard to brain function. First, the extent to which plasma GLU concentrations must rise to produce effects in rodent brain are never encountered in humans consuming GLU in their daily diets. Even very large increases in plasma GLU concentrations in fasting humans (produced in an experimental setting) do not push GLU into brain, as evidenced by the lack of changes in pituitary hormone secretion [22]. Such increases in plasma GLU levels never occur in humans ingesting even large amounts of MSG in their meals and diets (see above). Similar conclusions can be drawn from studies in nonhuman primates, in which marked increases in plasma GLU concentrations following MSG ingestion [32] failed to produce brain (arcuate nucleus) lesions [26]. Second, animals ingesting enormous amounts of MSG every day in their diets (up to $25,000 \mathrm{mg} / \mathrm{kg}$ bw/day in lactating females), even over multiple generations, experience none of the adverse effects reported to occur following enormous injected doses of MSG $[10,20]$. In this regard, it is noteworthy that breast milk free GLU concentrations are not increased in lactating women given a large oral dose of MSG that markedly increases plasma GLU concentrations [54]. Nursing infant intake of free GLU from breast milk is thus unaffected by maternal MSG ingestion. And, studies in monkeys show that GLU does not cross the placental barrier and raise fetal plasma GLU concentrations, even at GLU concentrations in maternal blood that exceed levels ever likely to be achieved by MSG ingestion (see reference [55]). Finally, it is important to note that MSG intake in the human diet is likely self-limiting, based on the fact that the perceived pleasantness of ingested MSG (MSG taste) diminishes markedly as its concentra- 
tion rises, in contrast to the perceived pleasantness of sugar (sweet taste), which results in no such aversion at high concentrations [53]. Together, the findings from non-human primate and human studies provide important evidence that MSG in the food supply presents no hazard to the human brain.

\section{Ethics Statement}

The author has no ethical conflicts to disclose.

\section{Disclosure Statement}

The author is a scientific advisor to the International Glutamate Technical Committee.

\section{Funding Sources}

The Workshop preparation, setting, and attendance were supported by the International Glutamate Technical Committee (IGTC), Brussels. The views of the author are his own, and do not necessarily reflect those of the IGTC.

\section{References}

1 Olney JW: Brain lesions, obesity, and other disturbances in mice treated with monosodium glutamate. Science 1969;164:719-721.

2 Olney JW, Ho OL: Brain damage in infant mice following oral intake of glutamate, aspartate or cysteine. Nature 1970;227:609611.

3 Hawkins RA: The blood-brain barrier and glutamate. Am J Clin Nutr 2009;90:867S874 S.

4 Perez VJ, Olney JW: Accumulation of glutamic acid in the arcuate nucleus of the hypothalamus of the infant mouse following subcutaneous administration of monosodium glutamate. J Neurochem 1972;19:1777-1782.

5 Peruzzo B, Pastor FE, Blazquez JL, Schobitz K, Pelaez B, Amat P, Rodriguez EM: A second look at the barriers of the medial basal hypothalamus. Exp Brain Res 2000;132:10-26.

6 Brann DW, Mahesh VB: Excitatory amino acids: evidence for a role in the control of reproduction and anterior pituitary hormone secretion. Endocr Rev 1997;18:678-700.

7 Meldrum BS, Garthwaite J: Excitatory amino acid neurotoxicity and neurodegenerative disease. Trends Pharmacol Sci 1990;11:379-387.

8 Olney JW: Excitotoxins in foods. NeuroToxicology 1994; 15:535-544.

9 Pizzi WJ, Barnhart JE, Fanslow DJ: Monosodium glutamate administration to the newborn reduces reproductive ability in female and male mice. Science 1977;196:452-454.

10 Heywood R, Worden AN: Glutamate toxicity in laboratory animals; in Filer LJ Jr, Garattini S, Kare MR, Reynolds WA, Wurtman RJ (eds): Glutamic Acid: Advances in Biochemistry and Physiology. New York, Raven Press, 1979, pp 203-215.

11 Olney JW: Glutamate-induced neuronal necrosis in the infant mouse hypothalamus. An electron microscopic study. J Neuropathol Exp Neurol 1971;30:75-90.

12 Takasaki Y: Studies on brain lesion by administration of monosodium L-glutamate to mice. I. Brain lesions in infant mice caused by administration of monosodium L-glutamate. Toxicology 1978;9:293-305.
13 O’Hara Y, Iwata S, Ichimura M, Sasaoka M: Effect of administration routes of monosodium glutamate on plasma glutamate levels in infant, weanling and adult mice. J Toxicol Sci 1977;2:281-290.

14 O'Hara Y, Takasaki Y: Relationship between plasma glutamate levels and hypothalamic lesions in rodents. Toxicol Lett 1979;4:499505.

15 Takasaki Y: Studies on brain lesions after administration of monosodium L-glutamate to mice. II. Absence of brain damage following administration of monosodium L-glutamate in the diet. Toxicology 1978;9:307-318.

16 Rosenwasser AM, Boulos Z, Terman M: Circadian organization of food intake and meal patterns in the rat. Physiol Behav 1981;27:3339.

17 Takasaki Y, Matsuzawa Y, Iwata S, O'Hara Y, Yonetani S, Ichimura M: Toxicological studies of monosodium L-glutamate in rodents: relationship between routes of administration and neurotoxicity; in Filer LJ Jr, Garattini S, Kare MR, Reynolds WA, Wurtman RJ (eds): Glutamic Acid: Advances in Biochemistry and Physiology. New York, Raven Press, 1979, pp 255-275.

18 Price MT, Olney JW, Lowry OH, Buchsbaum S: Uptake of exogenous glutamate and aspartate by circumventricular organs but not other regions of brain. J Neurochem 1981;36: 1774-1780.

19 Davison AN, Dobbing J: Myelination as a vulnerable period in brain development. Br Med Bull 1966;22:40-44.

20 Anantharaman K: In utero and dietary administration of monosodium L-glutamate to mice: Reproductive performance and development in a multigeneration study; in Filer LJ Jr, Garattini S, Kare MR, Reynolds WA, Wurtman RJ (eds): Glutamic Acid: Advances in Biochemistry and Physiology. New York, Raven Press, 1979, pp 231-253.

21 Stegink LD, Reynolds WA, Filer LJ, Baker GL, Daabees TT, Pitkin RM: Comparative metabolism of glutamate in the mouse, monkey and man; in Filer LJ, Garattini S, Kare MR, Reyn- olds WA, Wurtman RJ (eds): Glutamic Acid: Advances in Biochemistry and Physiology. New York, Raven Press, 1979, pp 85-102.

22 Fernstrom JD, Cameron JL, Fernstrom $\mathrm{MH}$, McConaha C, Weltzin TE, Kaye WH: Shortterm neuroendocrine effects of a large oral dose of monosodium glutamate in fasting male subjects. J Clin Endocrinol Metab 1996; 81:184-191.

23 Graham TE, Sgro V, Friars D, Gibala MJ: Glutamate ingestion: the plasma and muscle free amino acid pools of resting humans. Am J Physiol 2000;278:E83-E89.

24 Bazzano G, D'Elia JA, Olson RE: Monosodium glutamate: feeding of large amounts in man and gerbils. Science 1970;169:12081209.

25 Himwich HE, Wolff K, Hunsicker AL, Himwich WA: Some behavioral effects associated with feeding sodium glutamate to patients with psychiatric disorders. J Nerv Ment Dis 1955;121:40-49.

26 Reynolds WA, Lemkey-Johnston N, Stegink LD: Morphology of the fetal monkey hypothalamus after in utero exposure to monosodium glutamate; in Filer LJ Jr, Garattini S, Kare MR, Reynolds WA, Wurtman RJ (eds): Glutamic Acid: Advances in Biochemistry and Physiology. New York, Raven Press, 1979, pp 217-229.

27 Abraham R, Dougherty W, Golberg L, Coulston F: The response of the hypothalamus to high doses of monosodium glutamate in mice and monkeys. Cytochemistry and ultrastructural study of lysosomal changes. Exp Mol Pathol 1971;15:43-60.

28 Abraham R, Swart J, Golberg L, Coulston F: Electron microscopic observations of hypothalami in neonatal rhesus monkeys (Macaca mulatta) after administration of monosodium-L-glutamate. Exp Mol Pathol 1975;23: 203-213.

29 Wen CP, Hayes KC, Gershoff SN: Effects of dietary supplementation of monosodium glutamate on infant monkeys, weanling rats, and suckling mice. Am J Clin Nutr 1973;26:803813 
30 Newman AJ, Heywood R, Palmer AK, Barry DH, Edwards FP, Worden AN: The administration of monosodium L-glutamate to neonatal and pregnant rhesus monkeys. Toxicology 1973;1:197-204.

31 Reynolds WA, Lemkey-Johnston N, Filer LJJ, Pitkin RM: Monosodium glutamate: absence of hypothalamic lesions after ingestion by newborn primates. Science 1971;172:13421344.

32 Stegink LD, Reynolds WA, Filer LJ, Pitkin RM, Boaz DP, Brummel MC: Monosodium glutamate metabolism in the neonatal monkey. Am J Physiol 1975;229:246-250.

33 Medhamurthy R, Gay VL, Plant TM: Repetitive injections of $\mathrm{L}$-glutamic acid, in contrast to those of N-methyl-d,l-aspartic acid, fail to elicit sustained hypothalamic GnRH release in the prepubertal male rhesus monkey (Macaca mulatta). Neuroendocrinology 1992;55: 660-666.

34 Gay VL, Plant TM: N-methyl-D,L-aspartate elicits hypothalamic gonadotropin-releasing hormone release in prepubertal male rhesus monkeys (Macaca mulatta). Endocrinology 1987;120:2289-2296.

35 Van de Kar LD: Neuroendocrine pharmacology of serotonergic (5-HT) neurons. Annu Rev Pharmacol Toxicol 1991;31:289-320.

36 Cowen PJ: Serotonin receptor subtypes in depression: evidence from studies in neuroendocrine regulation. Clin Neuropharmacol 1993;16(suppl 3):S6-S18.

37 van den Pol AN, Wuarin JP, Dudek FE: Glutamate, the dominant excitatory transmitter in neuroendocrine regulation. Science 1990; 250:1276-1278.

38 Brann DW: Glutamate: a major excitatory transmitter in neuroendocrine regulation. Neuroendocrinology 1995;61:213-225.
39 Carlson HE, Miglietta JT, Roginsky MS, Stegink LD: Stimulation of pituitary hormone secretion by neurotransmitter amino acids in humans. Metabolism 1989;38:1179-1182.

40 Terry LC, Epelbaum J, Martin JB: Monosodium glutamate: acute and chronic effects on rhythmic growth hormone and prolactin secretion, and somatostatin in the undisturbed male rat. Brain Res 1981;217:129-142.

41 Rubin RT, Poland RE, Lesser IM, Martin DJ: Neuroendocrine aspects of primary endogenous depression. V. Serum prolactin measures in patients and matched control subjects. Biol Psychiatry 1989;25:4-21.

42 Carlson HE, Wasser HL, Levin SR, Wilkins JN: Prolactin stimulation by meals is related to protein content. J Clin Endocrinol Metab 1983;57:334-338.

43 Ishizuka B, Quigley ME, Yen SS: Pituitary hormone release in response to food ingestion: evidence for neuroendocrine signals from gut to brain. J Clin Endocrinol Metab 1983;57:1111-1116.

44 Medhamurthy R, Dichek HL, Plant TM, Bernardini I, Cutler GB: Stimulation of gonadotropin secretion in prepubertal monkeys after hypothalamic excitation with aspartate and glutamate. J Clin Endocr Metab 1990;71: 1390-1392.

45 O'Hara Y, Iwata S, Ichimura M: Effect of administration routes of monosodium glutamate on plasma glutamate levels in infant, weanling and adult mice. J Toxicol Sci 1977;2:281-290.

46 Austin GL, Ogden LG, Hill JO: Trends in carbohydrate, fat, and protein intakes and association with energy intake in normal-weight, overweight, and obese individuals: 19712006. Am J Clin Nutr 2011;93:836-843.

47 Reeds PJ, Burrin DG, Jahoor F, Wykes L, Henry J, Frazer EM: Enteral glutamate is almost completely metabolized in first pass by the gastrointestinal tract of infant pigs. Am J Physiol 1996;270:E413-E418.
48 Stegink LD, Filer LJ, Baker GL: Plasma and erythrocyte amino acid levels in normal adult subjects fed a high protein meal with and without added monosodium glutamate. J Nutr 1982;112:1953-1960.

49 Stegink LD, Filer LJ, Baker GL: Plasma amino acid concentrations in normal adults fed meals with added monosodium L-glutamate and aspartame. J Nutr 1983;113:1851-1860.

50 Stegink LD, Filer LJ, Baker GL: Plasma glutamate concentrations in adult subjects ingesting monosodium L-glutamate in consomme. Am J Clin Nutr 1985;42:220-225.

51 Stegink LD, Filer LJ Jr, Baker GL, Bell EF: Plasma glutamate concentrations in 1-yearold infants and adults ingesting monosodium L-glutamate in consomme. Pediatr Res 1986; 20:53-58.

52 Tsai PJ, Huang PC: Circadian variations in plasma and erythrocyte glutamate concentrations in adult men consuming a diet with and without added monosodium glutamate. J Nutr 2000;130:1002S-1004S.

53 Yamaguchi S, Takahashi C: Hedonic functions of monosodium glutamate and four basic taste substances used at various concentration levels in single and complex systems. Agric Biol Chem 1984;48:1077-1081.

54 Baker GL, Filer LJJ, Stegink LD: Factors influencing dicarboxylic amino acid content of human milk; in Filer LJJ, Garattini S, Kare MR, Reynolds WA, Wurtman RJ (eds): Glutamic Acid: Advances in Biochemistry and Physiology. New York, Raven Press, 1979, pp 111123

55 Stegink LD, Pitkin RM, Reynolds WA, Filer LJ, Boaz DP, Brummel MC: Placental transfer of glutamate and its metabolites in the primate. Am J Obstet Gynecol 1975;122:70-78. 